\title{
Some Wild Canadian Orchids Benefit from Woodland Hiking Trails - and the Implications
}

\author{
Paul M. Catling and Brenda Kostiuk \\ 170 Sanford Avenue, Ottawa, Ontario K2C 0E9 Canada; email: catlingp@agr.gc.ca
}

Catling, P. M. and B. Kostiuk. 2011. Some wild Canadian orchids benefit from woodland hiking trails - and the implications. Canadian Field-Naturalist 125(2): 105-115.

To clarify the impact that trails have on orchids we compared the occurrence of orchids on the lightly trampled edges of bare trails, with the occurrence of orchids in the surrounding woodland and noted the degree of disturbance. A two-way mixed analysis of variance, using six trails from across Canada, indicated that location by distance strata interaction was lacking. Orchid densities were consistently higher within a few meters of the bare portion of a trail than further away. The width of the disturbance gradient for two well-used trails in parks in Bruce County, Ontario, was determined with regression to be within $1 \mathrm{~m}$ from the edge of the bare portion of the trail. Calypso bulbosa var. americana on trails in in Alberta, Epipactis helleborine and Goodyera oblongifolia on trails in Ontario, Goodyera repens on trails in Northwest Territories and all native orchids (cumulatively) on trails on Flowerpot Island, Ontario demonstrated consistent and significant increased abundance within the trail disturbance gradients in comparison to their occurrence in the surrounding forest. More flowering plants of Goodyera oblongifolia and mature capsules of Epipactis helleborine occurred in the trail disturbance gradient than beyond suggesting a beneficial impact on fecundity. The disturbance gradient effect likely includes light trampling which reduces competition, compacts soil, and exposes mineral soil. The effect also includes increased light and microclimate differences near to the path. Landscape managers should recognize that in some situations orchids may benefit greatly from trails and that trails may be better considered as a benefit than as a problem.

Key Words: Calypso bulbosa var. americana, Epipactis helleborine, Goodyera oblongifolia, Goodyera repens, disturbance, trails, paths, conservation, management, rare plants, Ontario, Alberta, Northwest Territories, Canada.

Although there is an extensive literature on the impacts of trails on vascular plants (e.g., Liddle 1975; Jordan 2000; Ferguson et al. 2010), and it includes a few useful articles concerning the minimization of conflicts between recreational uses of trails and conservation on trails (Cole 1993), very few studies have emphasized the beneficial effects of trails (Bratton 1985; Sinclair and Catling 2000). However, it is widely known that there is a disturbance gradient and zonation of plants extending from the bare portion of a trail into the surrounding woodland and it is also known that the trail flora includes characteristic woodland species that increase in abundance near the trail (Dale and Weaver 1974; Bright 1986; Benninger-Truax et al. 1992; Ferguson et al. 2010). Trails may also increase native biodiversity (Roovers et al. 2005) and act as dispersal corridors for some species (Benninger-Truax et al. 1992).

Many native Canadian orchids are associated with disturbed situations, including trails (Catling 1996, page 18), but there is little information on the trail effect. In one of the few quantitative studies, Bratton (1985) found that populations of Galearis spectabilis (L.) Raf. (Showy Orchis) were denser close to trails. Other studies have shown that trampling in orchid habitat increases soil compaction and decreases the abundance of fungivorous nematodes (Light and MacConaill 2007, 2008, 2009). How this affects orchids remains unclear, although a beneficial effect of trails was suggested in one of these studies (Light and MacConnail
2009). Despite the lack of specific information, it should not be surprising that some orchids benefit from trail-related disturbances, since this has been documented for a number of plants including rare species (e.g., Sinclair and Catling 2000).

An understanding of the disturbance effects of trails on terrestrial orchids would also be relevant to conservation and management. Natural areas are frequently maintained for both conservation and recreational purposes. Both of these objectives require sensible decisions. In a few instances the closure of a trail to prevent orchids from being trampled has failed to take into account the fact that the orchids might not have been there in the first place without the trail (personal observation). There are numerous instances of populations of rare plants in high traffic areas that declined or disappeared as soon as the population was protected from disturbance with a fence (personal observation). Recreation - specifically the use of trails - is economically important, valued at $\$ 56$ million annually in the US (compared to $\$ 66$ million in wildlife viewing and \$13 million in hunting, (Frantz 2007*; Kelley 2006*). Recreation is also part of the human experience of nature, which helps to develop a protective attitude. Thus it is undesirable to restrict human traffic, from both a recreational and a conservation perspective, unless it is necessary to preserve a species or population.

We suspect that trails used by humans often lead to an increase in biodiversity and contribute to the pro- 
TABLE 1. Locations, species recorded, near and far trail distances compared, number of trail sections for counts, and the length of the sections for 6 trails used in a study of orchids on trails.

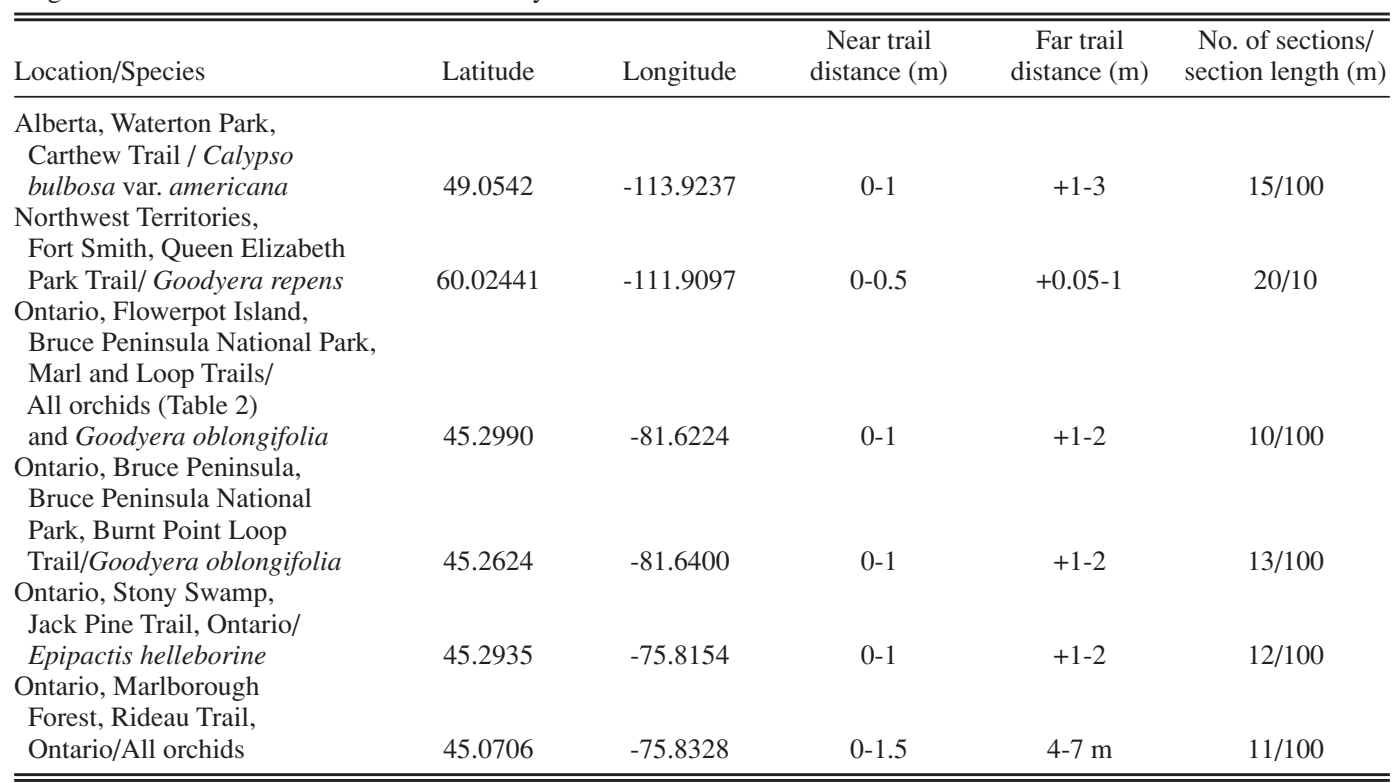

tection of rare and attractive plants, despite occasional trampled plants. Here we analyze data concerning the presence of orchids along trails to further explore this hypothesis.

\section{Methods}

\section{Study areas and sampling procedures}

In all cases the substrate of trails studied was natural. Trails created with wood chips, planks, or the crushed stone used for patios, were not included. Sites were chosen by convenience and on the basis of the presence of relatively large numbers of one or more species of orchids that would allow quantitative data to be collected. The data were gathered in such a way as to facilitate comparison of frequencies near a trail, i.e., within the disturbance gradient (usually $<1.5 \mathrm{~m}$ ), and far from a trail $(>1.5 \mathrm{~m})$. Near and far areas surveyed were either of similar size or the areas far from the trail were larger (Table 1). Distances were always measured from the edge of the bare portion of the trail. The homogeneity of vegetation before paths were created is assumed. This is not an unreasonable assumption and it is accounted for by a sufficient number of sample regions along a path through an essentially homogeneous landscape that includes similar substrates and slopes. In all cases the orchid plants were flowering or fruiting at the time of the surveys (indicated below) and all were conspicuous and readily identified. The several study areas were selected to demonstrate the widespread occurrence of the phenomenon. Locations of trails studied are indicated in Fugure 1 and given in Table 1 .
1. Alberta, Waterton Lakes National Park of Canada. The Carthew-Alderson Trail in Waterton Lakes National Park of Canada passes through Lodgepole Pine (Pinus contorta var. latifolia) - Engelmann's Spruce (Picea engelmannii) forest. This trail is cut out of a steep mountain slope with a gradual to steep bank on one side and descending slope on the other. The disturbed part of the trail on the bank side is characteristically 1 meter wide and the slope varies from $5-10^{\circ}$ beside the bare portion of the trail rising to a slope of $80-90^{\circ}$ at a distance of $1 \mathrm{~m}$. Most orchid plants occur in the region of the lower slope where occasional trampling occurs and where some mineral substrate is often exposed. Sampling, on 25 June 2010, involved 15 consecutive sections of $100 \mathrm{~m}$ each with data on occurrence of Calypso bulbosa (L.) Oakes var. americana (R.Br.) Luer (Fairy Slipper) on the slope side of the trail, either within $1 \mathrm{~m}$ of the edge of the bare portion of the trail, or between +1 and $3 \mathrm{~m}$ from the edge of the trail. This trail had 40 hikers during the four hour period that we were there and thousands probably use it annually.

2. Northwest Territories, Queen Elizabeth Territorial Park. The trail from a parking lot and camping area to a high bank overlooking the Slave River in Queen Elizabeth Territorial Park, was surveyed on 3 July 2010. Goodyera repens (L.) R. Br. (Dwarf Rattlesnakeplantain) was the only orchid present. The trail goes through mature Jack Pine (Pinus banksiana) - White Spruce (Picea glauca) forest. The number of plants of Goodyera repens was recorded both $0-0.5 \mathrm{~m}$ and $+0.5-1.0 \mathrm{~m}$ from the edge of the bare portion of the trail in 20 consecutive sections of $10 \mathrm{~m}$ each. Thus 


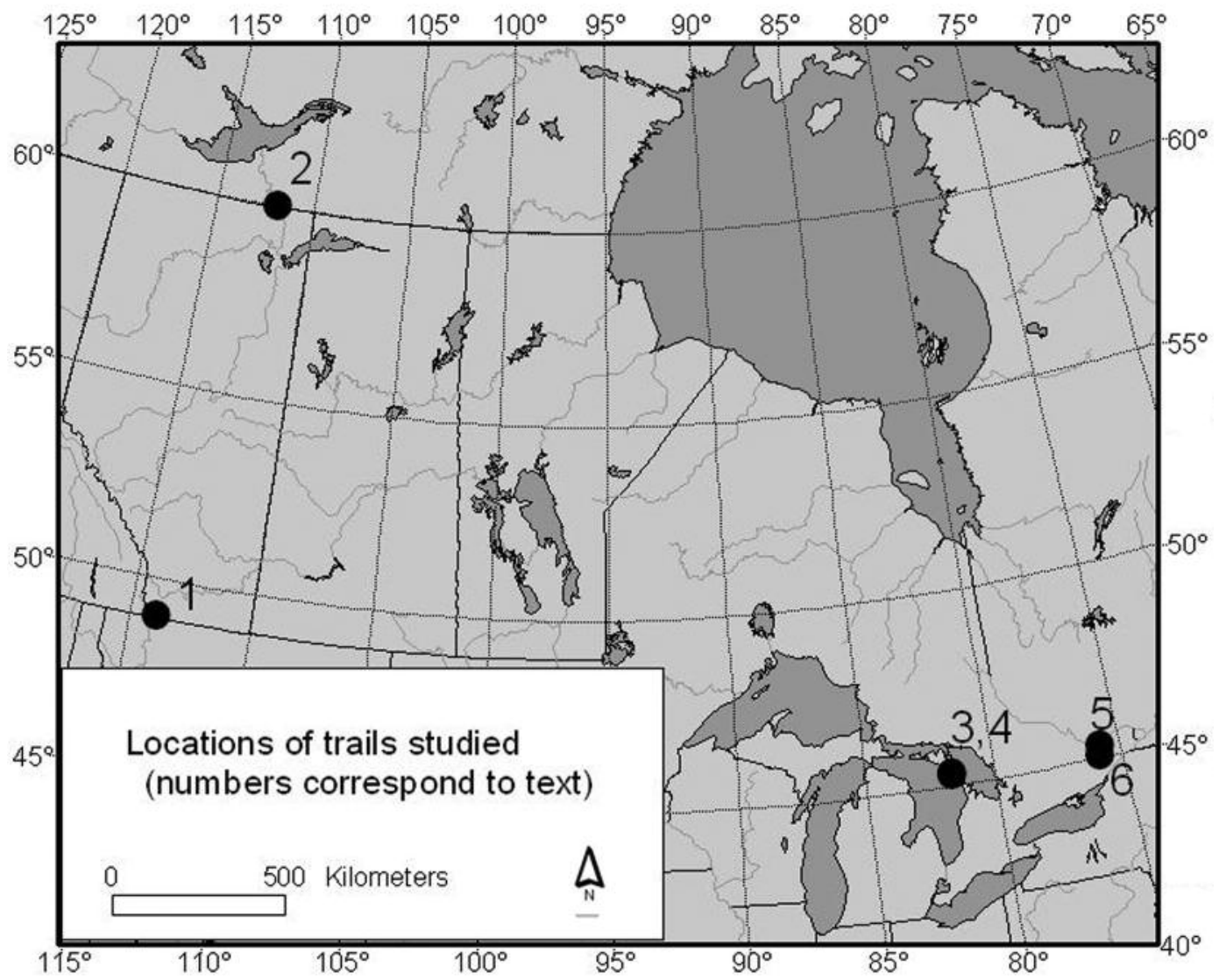

FIGURE 1. Locations of trails studied (dots). The numbers of the dots correspond to the numbers in the text.

areas compared were $100 \mathrm{~m}^{2}$. The bare portion of the trail was $1 \mathrm{~m}$ wide. Local residents suggested that on most days during July and August, 100 people use this trail each day.

3. Ontario, Fathom Five National Marine Park of Canada. The Marl Pond Trail and the interior portion of the Loop Trail on Flowerpot Island are located in Fathom Five National Marine Park of Canada, off Tobermory in Georgian Bay of Lake Huron. The trails traverse woodland of Eastern White Cedar (Thuja occidentalis), Trembling Aspen (Populus tremuloides), Balsam Fir (Abies balsamea), and Sugar Maple (Acer saccharum). The most frequent orchid here was Goodyera oblongifolia (Menzies' Rattlesnake Plantain). At this site the data collected on 1 August 2010 included distance from the edge of the bare portion of the path up to $2 \mathrm{~m}$ distant for all native orchids on either side of 10 sections of each trail, the sections each being continuous and $100 \mathrm{~m}$ long. The data were also divided for comparison as $0-1 \mathrm{~m}$ and $+1-2 \mathrm{~m}$ from the edge of the bare portion of the trail. The trail is undu- lating with a bare portion $0.5-1 \mathrm{~m}$ wide. Most of the Marl Pond Trail (Figure 2) was surveyed excepting the last few hundred $\mathrm{m}$ through open rock scree but much of the dry, rugged central plateau portion of the interior part of the Loop Trail was omitted due to scarcity of orchids and narrowness of trail due to boulders and large rocks. One hundred and twenty-five people passed us on the Loop Trail within 2 hours, mostly in groups and often with children. During the high point of the season in July and August, we suspect that at least a few hundred people use this trail each day.

4. Ontario, Bruce Peninsula National Park of Cana$d a$. The entire length of the south side of the Burnt Point Loop Trail in Bruce Peninsula National Park of Canada, in Ontario, was surveyed on 2 August 2010. The trail traverses woodland of Eastern White Cedar, Trembling Aspen, and Balsam Fir. Here data were collected from the bare portion up to $2 \mathrm{~m}$ distant for all native orchids on either side of 13 consecutive sections of the trail, the sections each being continuous and each $100 \mathrm{~m}$ long. The trail is undulating with a bare 
portion $0.5-1 \mathrm{~m}$ wide. Increasingly exposed rocks and roots have resulted in expansion of trail width to $2 \mathrm{~m}$ in some areas. Sixty-five people passed us on this trail late on a rainy afternoon. The annual use in spring, summer and fall is estimated as thousands.

5. Ontario, Ottawa, Stony Swamp, Jack Pine Trail. Epipactis helleborine (L.) Crantz (Broadleaf Helleborine) was surveyed along 12 consecutive sections of trial, each $100 \mathrm{~m}$ long. The trail passes through Jack Pine-Sugar Maple forest over sandstone. In each section the number of plants $0-1 \mathrm{~m}$ and $+1-2 \mathrm{~m}$ from the trampled edge of the trail was recorded. The trail has a central bare portion at least $1 \mathrm{~m}$ wide and is used by thousands of people each year. Data was collected on 27 August 2010.

6. Ontario, Marlborough Forest, Rideau Trail. The hiking trail passes through Eastern White Cedar, Balsam Fir and White Spruce forest on shallow soil over limestone. Orchids here included Cypripedium arietinum R. Br. (Ram's-head Lady's-slipper), Cypripedium parviflorum var. pubescens (Greater Yellow Lady'sSlipper), Epipactis helleborine (L.) Crantz, Platanthera aquilonis Sheviak (Northern Green Orchid), Platanthera hookeri (Torrey) Lindley (Hooker's Orchid) and Spiranthes lacera (Raf.) Raf. (Northern Slender Ladies-tresses). The trail is more open than the surrounding forest and tends to be invaded by young growth of the forest trees. This undergrowth is cut and is then usually dumped between 1 and $3 \mathrm{~m}$ off the trail thus creating a complicating factor (smothering of vegetation with organic matter) for comparisons involving the adjacent far trail area. As a result orchids were recorded here within $1.5 \mathrm{~m}$ of the bare trail edge on either side of the trail and this was compared with records from the $3 \mathrm{~m}$ wide track through the woods parallel to the trail but $4 \mathrm{~m}$ removed on the west side. The comparison involved 11 sections of one hundred $\mathrm{m}$ each and the data were gathered on 29 August 2010. The trail had experienced little recent use, evidently due to flooding of large sections. At this site Maianthemum stellatum (L.) Link.(False Solomon's Seal) was distinguished from non-flowering plants of Cypripedium arietinum by the more pubescent and non-winged stems and curving and sheathing leaves of the latter.

\section{Data Analysis}

We used the data collected (as described above and see Table 1) to perform four related analyses:

\section{(1) Overall trail effect}

We used all data on orchids along six trail segments to examine the effect of trail proximity. This was done by fitting a two way mixed ANOVA, with stratum (near, far) as a fixed factor, and location as a random factor, to the $\log 10+1$ transformed counts for each trail section. The transformation was necessary to stabilize the variance, and the 1 is added because $\log 10(0)$ is undefined, and some sections had counts of zero.

\section{(2) The trailside gradient}

In the case of the two trails (Fathom Five and Bruce Peninsula) data were available on actual distances of all recorded plants from the edge of the bare portion of the trail out to a distance of $2 \mathrm{~m}$. This not only provided a means of determining the extent of the trail effect on orchids, it also provided an evaluation of the probable width of the disturbance gradient. Regression along with correlation and analysis of variance (ANOVA) was used to determine the significance of the relationship. The shape and formula of the best fit regression line helped to define the distance at which abundance of orchids changed. The analysis was performed using the number of orchids in 20 consecutive $10 \mathrm{~cm}$ sections up to $200 \mathrm{~cm}$ from the bare edge of the trail.

\section{(3) Pairwise and independent comparisons}

Much of the analysis here involves instances based on adjacent occurrence (near to the trail and far from the trail) along consecutive sections of trail. Near is defined as 0 to $1.5 \mathrm{~m}$ or less (as indicated - Table 1) and far is defined as more than 0.5 or more commonly more than 1 or $1.5 \mathrm{~m}$. These distances are generally supported by the gradient analysis described above. However, the limits of the distances for the comparison to trailside areas were generally decided upon based on observation of what appeared to be a likely limit for the gradient based on changes in vegetation.

Since sections of trail within and outside a given distance share certain landscape features and have an extensive common boundary, they might be regarded as paired samples. On the other hand the near and far trail samples are actually not from the same source and are, to a large extent, independent. As a result of these paired and independent aspects, the data were analyzed both ways - as paired samples using the Paired t-test, the Sign Test and the Wilcoxon Signed Rank Test and as independent samples using the Mann-Whitney Wilcoxon test comparing medians and the KolmogorovSmirnov Test comparing distributions.

The Paired t-test, employing differences between pairs of observations, compares means and assumes normality considered as acceptable within limits of \pm 2 for both skewness and kurtosis. All other tests are nonparametric. The Sign Test and the Wilcoxon Signed Rank Test compare medians. Of the two the Wilcoxon, using ranks, explains more of the data (Sokal and Rolf 1995). The Kolmogorov-Smirnov Test has the advantage of providing a different perspective in comparing distributions to some extent independent of mean and variance, but the Mann-Whitney Wilcoxon test which compares ranks in the combined data is considered the best suited to the present data (Sokal and Rolf 1995). For all tests the significance was defined as less than 0.05 .

The amount and consistency of difference in numbers of orchids within and outside the disturbance gra- 


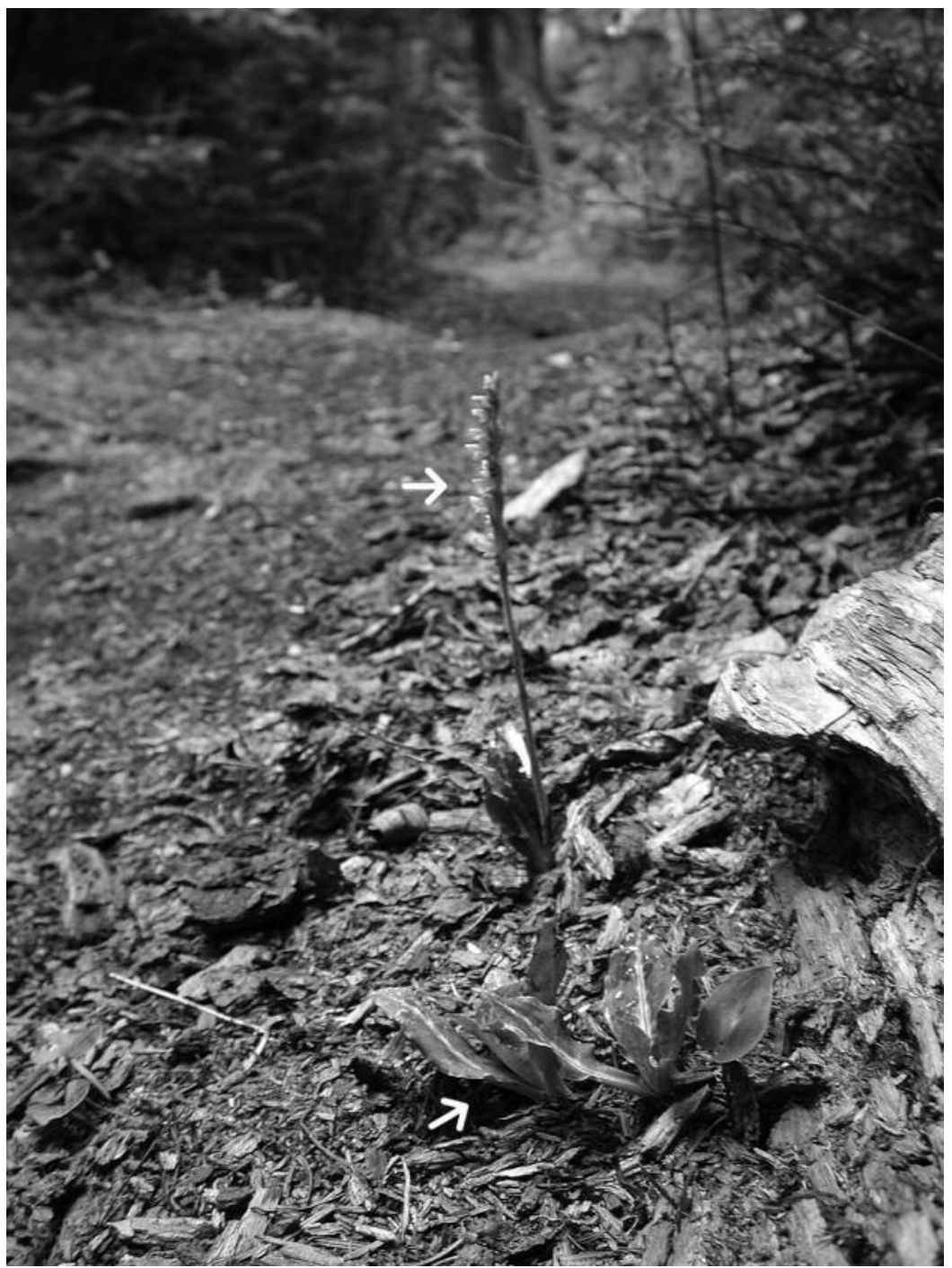

FIGURE 2. Goodyera oblongifolia (arrows) on the edge of the bare portion of the Marl Pond Trail on Flowerpot Island Flowerpot Island, Georgian Bay, Lake Huron, in Fathom Five National Marine Park of Canada, Ontario.

dient of consecutive trail sections were illustrated using simple plots with line graphs. The graphs were considered appropriate because the distributions are continuous distances from the start of the trail showing the pattern of corresponding differences encountered as one proceeds. All of the statistical procedures and plots utilized Statgraphics Centurion 15 software (Statpoint $\left.2005^{*}\right)$.

\section{(4) Effect on fecundity}

For Epipactis helleborine and Goodyera oblongifolia, numbers and proportions of capsules and flowering plants respectively near and far from the trail were tabulated. In the case of Goodyera oblongifolia, flowering condition was related to distance with analy- sis of variance and regression using the 10 consecutive components of distance from the bare trail edge.

\section{Results}

\section{(1) Overall trail effect}

Counts varied substantially among strata $(\mathrm{F}=104.7$, $\mathrm{df}=1,150, \mathrm{p}<0.001)$ and locations $(\mathrm{F}=19.9, \mathrm{df}=5$, $150, p<0.001$ ) with no evidence of a location by strata interaction $(\mathrm{F}=0.93, \mathrm{df}=5,150, \mathrm{p}=0.46)$ and no evidence of significant spatial autocorrelation within trails among adjacent sections. Orchid densities were, on average, higher in close proximity, a result that appears to be consistent across the range of locations investigated (Figure 3). 

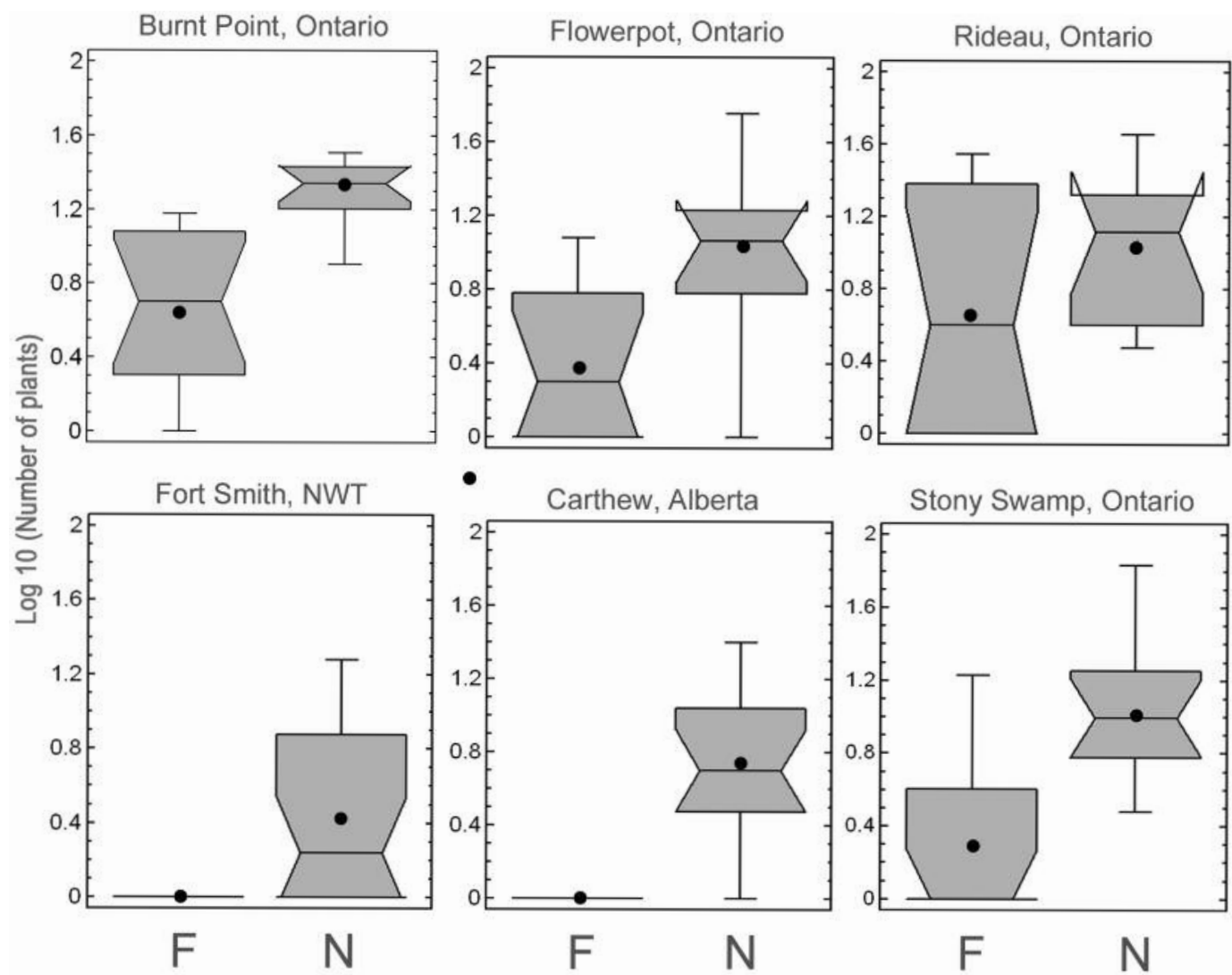

Far $(\mathrm{F})$ and near $(\mathrm{N})$ trail distance strata

FIGURE 3. Box-and-whisker plots showing $\log 10$ (number of orchid plants) for far $(\mathrm{F})$ and near $(\mathrm{N})$ distance strata of six woodland trails. The boxes represent the middle half of the data. Vertical lines through the boxes indicate the range of values. Horizontal lines at the notch in the boxes are medians. The dot shows the location of the sample mean.

\section{(2) The trailside gradient}

The best fit for the regression line derived from the data on number of plants of all native orchids with respect to distance from the bare portion of the trails on Flowerpot Island (Figure 4) is the reciprocal-X model with Number of plants $=-3.17474+74.6288 /$ number of consecutive $10 \mathrm{~cm}$ distance $(\mathrm{r}$-squared $=$ $95.75 \%$ ). Clearly the number of plants declines with increasing distance from the bare portion of the path and there is a major change in slope at a distance of $0.2 \mathrm{~m}$ and at $0.4 \mathrm{~m}$ distance indicating a major change in the gradient at this point. The correlation coefficient is -0.98753 indicating a strong relationship which is highly significant (ANOVA $\mathrm{F}=405.74, \mathrm{P}=0.0000$ ).

A similar result was obtained for the regression line derived from the data on number of plants of Goodyera oblongifolia on the Burnt Point Trail (Bruce Peninsula National Park) over distance from the bare portion of the trail (Figure 5). In this case the exponential model provided the best fit with Number of plants $=\exp (4.37993-0.148863 \times$ number of consecutive
TABLE 2. Numbers of eight species of orchids including Calypso bulbosa americana, Corallorhiza maculata, Corallorhiza trifida, Goodyera oblongifolia, Goodyera repens, Piperia unalascensis, Platanthera aquilonis, and Platanthera hookeri recorded along the Marl Pond and Loop trails on Flowerpot Island, Fathom Five National Marine Park, at a distance of either 0-1 $\mathrm{m}$ from the trampled edge or 1-2 $\mathrm{m}$ from the trampled edge on 1 August 2010.

\begin{tabular}{lcc}
\hline \hline Species & $\begin{array}{c}0-1 \mathrm{~m} \\
\text { from edge }\end{array}$ & $\begin{array}{c}1-2 \mathrm{~m} \\
\text { from edge }\end{array}$ \\
\hline Calypso bulbosa var. americana & 2 & 0 \\
Corallorhiza maculata & 4 & 0 \\
Corallorhiza trifida & 2 & 0 \\
Goodyera oblongifolia & 150 & 27 \\
Goodyera repens & 5 & 2 \\
Piperia unalascensis & 2 & 0 \\
Platanthera aquilonis & 4 & 0 \\
Platanthera hookeri & 3 & 0 \\
Totals & 172 & 29 \\
\hline \hline
\end{tabular}


TABLE 3. Two sample comparison significance tests for data on orchids adjacent to and distant from trails in various locations. Paired tests include t-Test, Sign Test and Wilcoxon Signed Rank Test and independent tests include Mann-Whitney Wilcoxon Test and Kolmogorov-Smirnov Test (K-S). S = standard skewness for the two-sample comparison. $\mathrm{K}=$ standard kurtosis for the two sample comparison. See Methods for details on data collection for each of the 8 sites. K-S = Kolmogorov-Smirnoff Test.

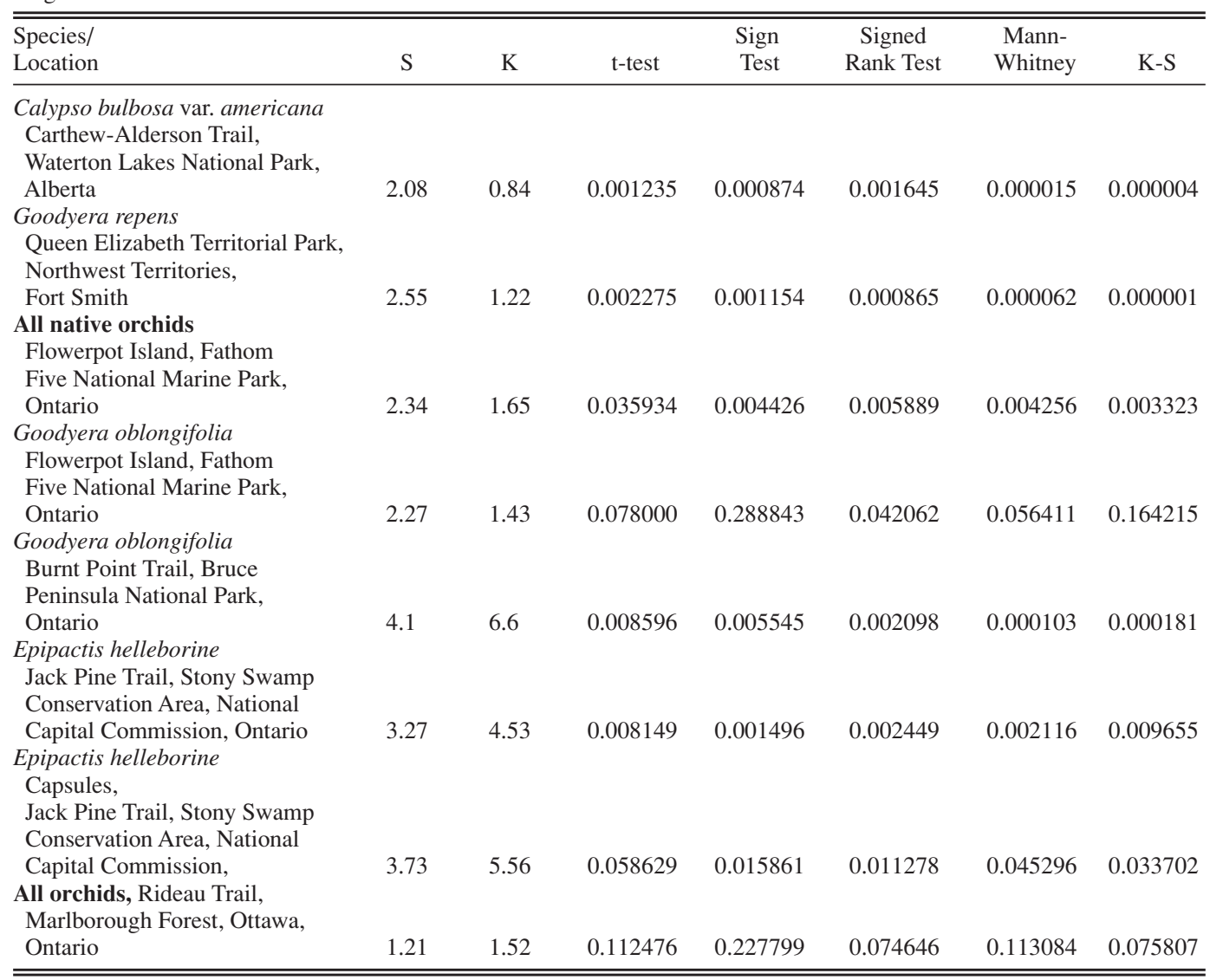

$10 \mathrm{~cm}$ distance $(\mathrm{r}$-squared $=74.20 \%)$. Again the number of plants declines with increasing distance from the bare portion of the trail but the major change in slope is at a distance of $1 \mathrm{~m}$. These results were also significant with the correlation coefficient $=-0.861398$ indicating a moderately strong relationship and ANOVA $\mathrm{F}=51.77, \mathrm{P}=0.0000$.

\section{(3) Pairwise and Independent comparisons}

In the study situations, Calypso bulbosa, Epipactis helleborine, Goodyera oblongifolia, Goodyera repens and all native orchids (cumulatively) on the two Flowerpot Island trails (Table 2) demonstrated consistent (Figures 2, 6-13) and significant (Table 3) increased abundance close to trails in comparison with the number of orchids farther from trails in the surrounding forest. Along a section of the Rideau Trail in eastern Ontario, orchids (Table 4) were more abundant near the trail but the effect was not significant (Table 3).
TABLE 4. Numbers of six species of orchids including Cypripedium arietinum, Cypripedium parviflorum, Epipactis helleborine, Platanthera aquilonis, Platanthera hookeri and Spiranthes lacera recorded along a trail $(1.5 \mathrm{~m}$ from the trampled portion) and along a woodland track parallel to the Rideau Trail in the Marlborough Forest, eastern Ontario.

\begin{tabular}{lcc}
\hline \hline Species & $\begin{array}{c}\text { Beside trail } \\
(1-1.5 \mathrm{~m})\end{array}$ & $\begin{array}{c}\text { Off trail } \\
(4-7 \mathrm{~m})\end{array}$ \\
\hline $\begin{array}{l}\text { Cypripedium arietinum } \\
\text { Cypripedium parviflorum } \text { var. }\end{array}$ & 42 & 62 \\
pubescens & 36 & 21 \\
Epipactis helleborine & 37 & 21 \\
Platanthera aquilonis & 2 & 0 \\
Platanthera hookeri & 1 & 4 \\
Spiranthes lacera & 0 & 1 \\
Totals & 118 & 109 \\
\hline \hline
\end{tabular}




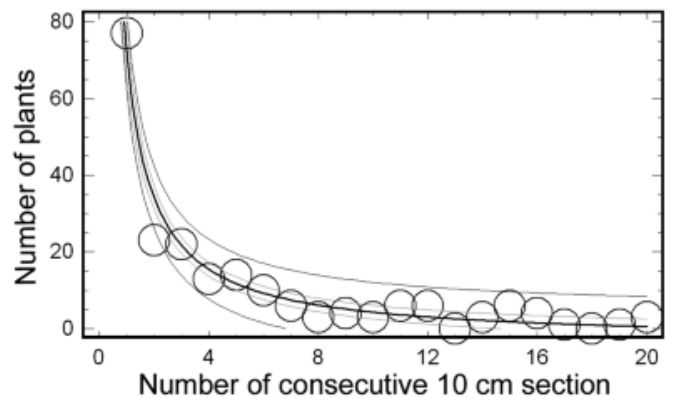

FIGURE 4. Regression line derived from the data on number of plants of all orchids with respect to distance from the bare portion of the Flowerpot Island trails (Bruce Peninsula National Park, Ontario). The best fit line is the reciprocal $-\mathrm{X}$ model with Number of plants $=-3.17474+74.6288 /$ number of consecutive $10 \mathrm{~cm}$ distances. The outer lines are the $95 \%$ prediction intervals for new observations. The inner lines are the $95 \%$ confidence intervals for the mean of many observations.

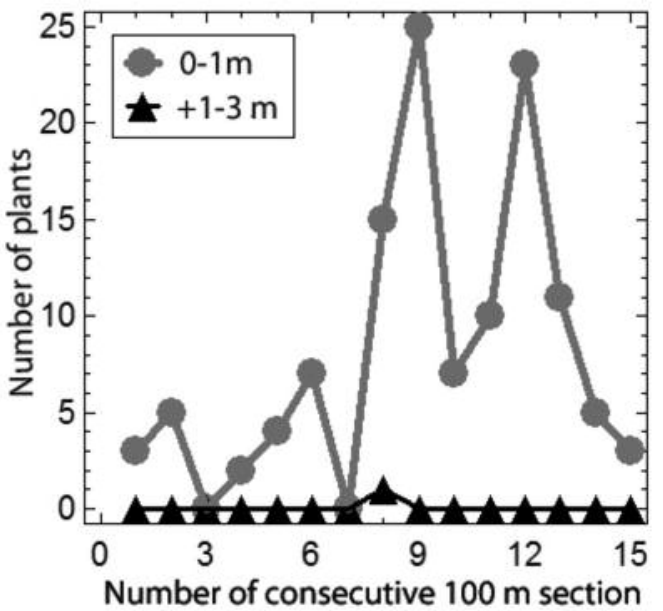

FIGURE 6. Plot of number of plants of Calypso bulbosa within $1 \mathrm{~m}$ of the trampled section of trail (dots) or 1-3 m off the trail (triangles) along 15 consecutive sections of $100 \mathrm{~m}$ each of the Carthew-Alderson Trail in Waterton Lakes National Park of Canada, Alberta, 25 June 2010.

The standard skewness and standard kurtosis values do exceed the desirable limits for the paired t-test, but they do not necessarily invalidate the results.

\section{(4) Effect on fecundity}

Although there were three times as many flowering plants of Goodyera oblongifolia within $1 \mathrm{~m}$ of the Burnt Point Loop trail (Bruce Peninsula National Park) as there were beyond $1 \mathrm{~m}$ (105 plants versus 34), a significantly higher proportion of the plants further

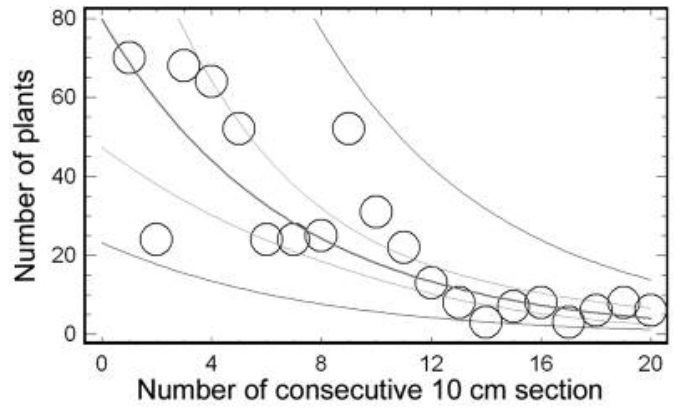

FIGURE 5. Regression line derived from the data on number of plants of Goodyera oblongifolia with respect to distance from the bare portion of the Burnt Point Loop Trail near Tobermory, in Bruce Peninsula National Park of Canada, Ontario, 2 August 2010. The best fit line is the exponential model with number of plants $=\exp (4.37993-0.148863 \times$ number of consecutive 10 -cm distances). The outer lines are the $95 \%$ prediction intervals for new observations. The inner lines are the $95 \%$ confidence intervals for the mean of many observations.

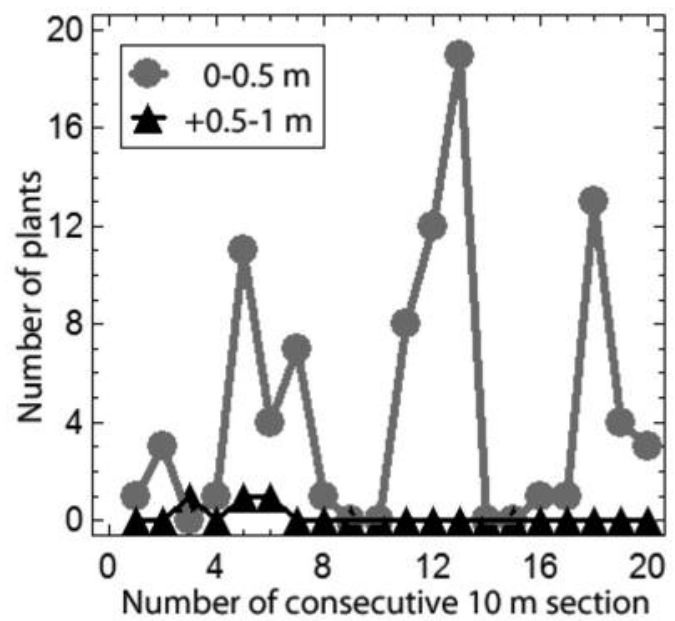

FIGURE 7. Plot of number of plants of Goodyera repens in Queen Elizabeth Territorial Park, Northwest Territories, $0-0.5 \mathrm{~m}$ (dots) or $0.5-1.0 \mathrm{~m}$ (triangles) from the trampled portion of the trail in 20 consecutive sections of $10 \mathrm{~m}$ each, 3 July 2010.

from the edge of the trail were flowering (ANOVA $\mathrm{F}$ $=12.18, \mathrm{P}=0.0005)$. Likewise for the two Flowerpot Island trails (Fathom Five National Marine Park) there were more than twice as many flowering plants within $1 \mathrm{~m}$ of the bare portion of the trail as there were beyond $1 \mathrm{~m}$ (50 plants versus 21). However, a significantly higher proportion of the plants further from the trail edge were flowering (ANOVA $\mathrm{F}=44.91$, $\mathrm{P}=0.0000)$. With respect to capsules of Epipactis 


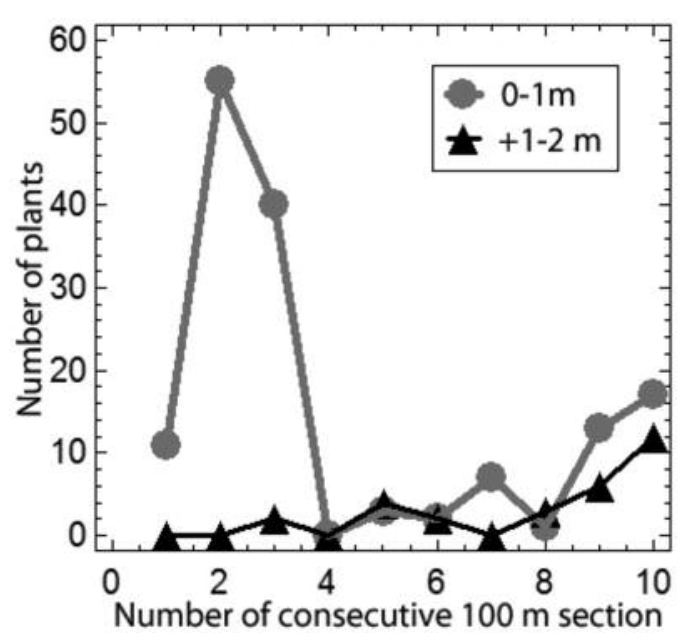

FIGURE 8. Plot of number of plants of Goodyera oblongifolia either $0-1 \mathrm{~m}$ (dots) or 1-2 $\mathrm{m}$ (triangles) from the bare portion of the trails in 10 consecutive sections of $100 \mathrm{~m}$ each on Flowerpot Island, Georgian Bay, Lake Huron, in Fathom Five National Marine Park of Canada, Ontario, 1 August 2010.

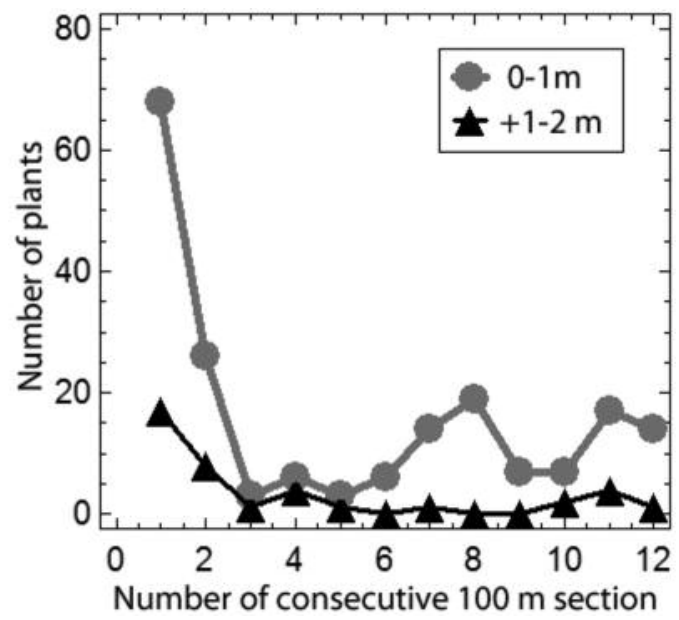

FIGURE 10. Plot of number of plants of Epipactis helleborine either $0-1 \mathrm{~m}$ (dots) or 1-2 m (triangles) from the bare portion of the trail along 12 consecutive sections of $100 \mathrm{~m}$ each, Jack Pine Trail in Ottawa (Stony Swamp Conservation Area, National Capital Commission) on 27 August 2010.

helleborine, more capsules developed near to the bare part of the trail than further from it (Figure 11).

\section{Discussion}

(1 and 2) Overall trail effect and the trailside gradient Although not all trails conform to a rule (authors, personal observation), a beneficial effect of trails on

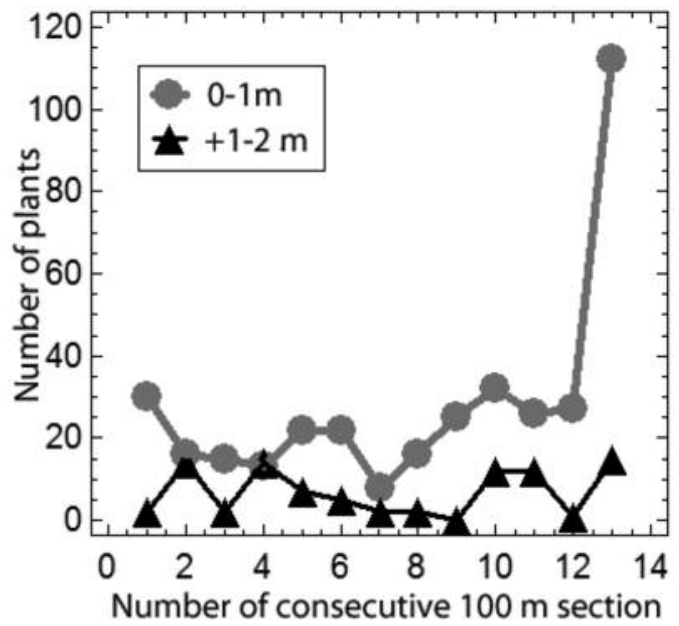

FIGURE 9. Plot of number of plants of Goodyera oblongifolia either $0-1 \mathrm{~m}$ (dots) or 1-2 $\mathrm{m}$ (triangles) from the bare portion of the trail in 20 consecutive sections of 100 m each, Burnt Point Loop Trail, Bruce Peninsula National Park of Canada, Ontario, 2 August 2010.

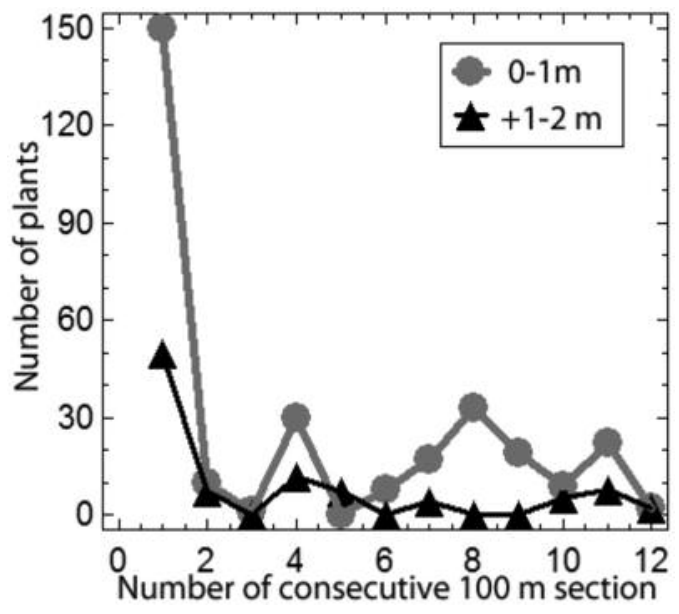

FIGURE 11. Plot of number of capsules on plants of Epipactis helleborine either 0-1 m (dots) or 1-2 m (triangles) from the bare portion of the trail along 12 consecutive sections of $100 \mathrm{~m}$ each, Jack Pine Trail in Ottawa (Stony Swamp Conservation Area, National Capital Commission) on 27 August 2010.

orchids can be demonstrated from data collected across Canada. That there is a significant beneficial effect and that it occurs over a distance of less than $1.5 \mathrm{~m}$ from the bare portion of a woodland trail is not surprising in light of: (1) the general tendency for terrestrial orchids to respond positively to disturbance; and (2) the literature indicating a zonation of species and suggesting 


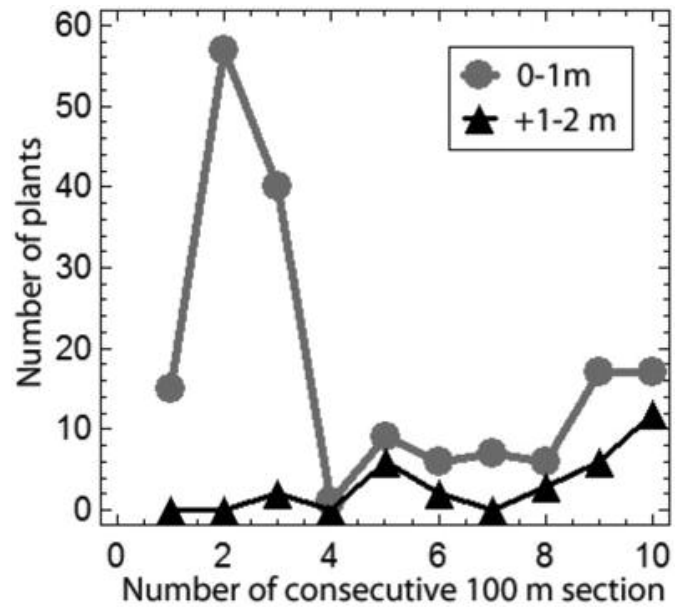

FIGURE 12. Plot of number of native orchids either $0-1 \mathrm{~m}$ (dots) or 1-2 $\mathrm{m}$ (triangles) from the bare portion of the of the trails in 10 consecutive sections of $100 \mathrm{~m}$ each, Flowerpot Island, Georgian Bay, Lake Huron, in Fathom Five National Marine Park of Canada, Ontario, 1 August 2010.

a trailside disturbance gradient of varying width (Bates 1935; Liddle 1975, 1997; Bright 1986; Benninger-Truax et al. 1992; Jordan 2000; Ferguson et al. 2010).

\section{(3) Pairwise and Independent comparisons.}

There are few previous data for the specific sites studied to compare with the results of the present study. Although the trampling study in Waterton Lakes National Park (Douglas et al. 1975*) was very comprehensive, there was no clear trend in the orchids present and this study was of too short a duration (one year) to indicate beneficial effects and it was designed only to elucidate short-term negative impacts. Much of the general literature has also assumed only negative effects and the experimental design has been developed to quantify negative impact. Although some studies noted previously (Dale and Weaver 1974; Bright 1986; Benninger-Truax et al. 1992; Ferguson et al. 2010) indicated a beneficial effect on some species, demonstration of a beneficial effect on orchids remains unique to Bratton (1985). Here that phenomenon is extended across Canada and to three native and one introduced species.

\section{(4) Effect on fecundity}

Light trampling beside the bare portion of a trail would be expected to damage plants and thus lead to reduced flowering and fruit production. Although proportionately less flower or fruit production occurred near the trail in the case of Goodyera oblongifolia and Epipactis helleborine respectively, this effect was not sufficient to reduce fecundity adjacent to the trail with

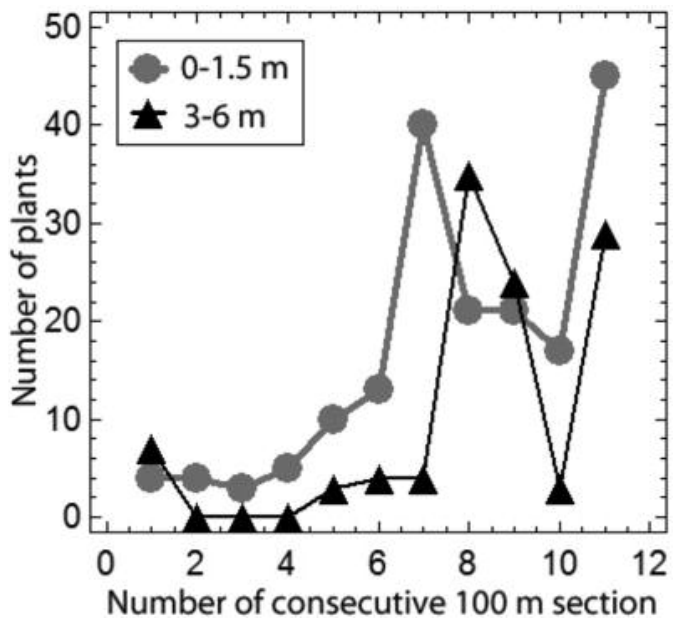

FIGURE 13. Plot of number of native orchid plants either $0-1.5 \mathrm{~m}$ from the bare portion of the trail on either side of the trail (dots) or along a parallel line through the woodland $3 \mathrm{~m}$ wide (triangles) and $4 \mathrm{~m}$ from the bare edge of the trail in 11 trail sections, Rideau Trail (Marlborough Forest, City of Ottawa), eastern Ontario, 29 August 2010.

respect to the adjacent forest because of the much larger number of plants adjacent to the trail. In the case of Cypripedium acaule Ait. (Pink Lady's-slipper) studied by Bratton (1985), there was no indication of an effect on density, but there was significantly reduced flowering near to the trail. This was attributed primarily to poaching.

\section{Mechanisms of the trail effect}

Many studies have documented a zonation from the bare portion of a trail into the surrounding habitat (Bates 1935; Liddle 1975, 1997; Benninger-Truax et al. 1992; Jordan 2000) and attributed it to light trampling reducing competition, compacting the soil, and exposing mineral soil, and to increased light and microclimate differences near to the path. During our surveys of the study trails, people were often seen stepping off the bare part of the trail to let others pass, or stepping off the edge of the trail accidentally or walking on both edges of the bare portion of the trail when walking two or three abreast. This is observed to kill some plants thus reducing competition for others that do survive and it results in a number of effects that are outlined above. The disturbance gradient becomes a clearly distinctive habitat to which some species are adapted. For example, on the Northwest Territories trail studied, the edges of the bare portion of the trail had more species of graminoid plants, much fewer species of moss, some bare soil and rare or restricted species such as Botrychium lunaria (L.) Sw. (Common Moonwort). 


\section{Management Implications}

Protection with fences may be appropriate in many cases, such as alpine vegetation growing on mountaintop lookouts (Willard and Marr 1971), and restricted access may be necessary in order to reduce poaching (Bratton 1985) but disturbance along trails may also be beneficial. There is a general tendency to consider trails only as problematic (e.g., Cole 1993; Jordan 2000). This has lead to restrictions including fences, trail closures and signs requiring people not to step off trails. The result of these restrictions can be reduced populations of rare plants, reduced experience of nature by people leading to less interest in conservation, and reduced income from recreation. A trail may be a problem, but it may not. Trails are not only good for people; they are sometimes (perhaps often) also good for rare plants, and particularly for some orchids, the most popular of native plants and a useful group of environmental indicators. A complaint about a trailside orchid plant knocked over by a hiker, should take into account the fact that the hikers may be the reason that the plant was there in the first place and that overall, hikers may often significantly improve orchid habitat.

\section{Acknowledgements}

Peter L. Achuff assisted with work at Waterton National Park and Bill Caulfield-Brown assisted with studies in Bruce Peninsula National Park. Dr. C. Scott Findlay, University of Ottawa, assisted with statistical analyses.

\section{Documents Cited (marked $*$ in the text)}

Douglas, G. W., J. A. S. Nagy, and G. W. Scotter. 1975. Effects of human and horse trampling on natural vegetation, Waterton Lakes National Park. Canadian Wildlife Service, Edmonton, Alberta. 129 pages.

Frantz, J. 2007. The value of hiking - economic benefits of hiking and non-motorized outdoor recreation. Washington Trails Association. 9 pages. http://webcache.googleuser content.com/search?hl=en\&q=cache:GZ5CMvHTlzEJ:ht tp://www.wta.org/trail-news/publications/Value-of-Hiking .pdf [accessed 24 March 2011]

Kelley, J. 2006. U.S. impact of outdoor recreation: $\$ 730$ billion. Outdoor Industry Foundation, Fall 2006 report. Rocky Mountain News. ESPN and Outdoor Industry Association. and (http://www.outdoorindustry.org/images/researchfiles/ RecEconomypublic.pdf?26) [accessed 24 March 2011].

Statpoint Inc. 2005. Statgraphics Centurion 15. Herndon, Virginia.

\section{Literature Cited}

Bates, G. H. 1935. The vegetation of footpaths, sidewalks, cart-tracks and gateways. Journal of Ecology 23: 463-487.

Benninger-Truax, M., J. L. Vankat, and R. L. Schaefer. 1992. Trail corridors as habitat and conduits for movement of plant species in Rocky Mountain National Park, Colorado. Landscape Ecology 6(4): 269-278.
Bratton, S. P. 1985. Effects of disturbance by visitors on two woodland orchid species in Great Smoky Mountains National Park, USA. Biological Conservation 31: 211-227.

Bright, J. A. 1986. Hiker impact on herbaceous vegetation along trails in an evergreen woodland of central Texas. Biological Conservation 36: 53-69.

Catling, P. M. 1996. 4.2 In situ conservation. Pages 15-23 in Orchids - status survey and conservation action plan. Edited by E. Hagsater, and V. Dumont. IUCN/SSC Orchid Specialist Group. International Union for the Conservation of Nature/Species Survival Commssion (IUCN/SSC) Orchid Specialist Group. Gland, Switzerland and Cambridge, UK. 153 pages.

Cole, D. N. 1993. Minimizing conflict between recreation and nature conservation. Pages 105-122 in Ecology of Greenways: Design and Function of Linear Conservation Areas. Edited by D. S. Smith and P. C. Hellmund. University of Minnesota Press. Minneapolis, Minnesota.

Dale, D., and T. Weaver. 1974. Trampling effects on vegetation of the trail corridors of north Rocky Mountain forests. Journal of Applied Ecology 11(2): 767-772.

Ferguson, A., J. Kirkpatrick, and E. Pharo. 2010. Variability in the incidence and characteristics of animal paths in montane vegetation. Plant Ecology and Diversity 3(1): 917.

Jordan, M. 2000. Ecological impacts of recreational use of trails: a literature review. The Nature Conservancy, Cold Spring Harbour, New York, New York.

Liddle, M. J. 1975. A theoretical relationship between the primary productivity of vegetation and its ability to tolerate trampling. Biological Conservation 8: 251-255.

Liddle, M. J. 1997. Recreation Ecology. Chapman and Hall, London.

Light, M. H. S., and M. McConnaill. 2007. Effects of trampling on a terrestrial orchid environment. Lankesteriana 7(1-2): 294-298.

Light, M. H. S., and M. McConnaill. 2008. Watch your step: Possible consequences of walking off the trail. Orchids 77: 128-132.

Light, M. H. S., and M. McConnaill. 2009. Visitor impact and sustainability. Pages 116-125 in North American Native Orchid Conservation - Preservation, Propagation, and Restoration. Edited by J. Sharma. Conference Proceedings of the Native Orchid Conference, Inc., Green Bay, Wisconsin, June 12 - 16, 2009. Native Orchid Conference, Inc., P.O. Box 29010, Greensboro, North Carolina 274299010. 131 pages, plus CD.

Roovers, P. 2005. Impact of outdoor recreation on ecosystems: towards an integrated approach. $\mathrm{PhD}$, Katholieke Universiteit Leuven. 188 pages. https://lirias.kuleuven.be/ bitstream/1979/62/2/PhD.pdf [accessed 25 Aug. 2010]

Sinclair, A., and P. M. Catling. 2000. Ontario Goldenseal, Hydrastis canadensis, populations in relation to habitat size, paths, and woodland edges. Canadian Field-Naturalist 114(4): 652-655.

Sokal, R. R., and F. J. Rohlf. 1995. Biometry, $3^{\text {rd }}$ edition. W. H. Freeman, New York.

Willard, B., and J. Marr. 1971. Recovery of alpine tundra under protection after damage by human activity in the Rocky Mountains of Colorado. Biological Conservation 3: 131-190. 